\title{
Evaluation Of Challenges Of Facilities Management In The Aviation Sector Of The Nigerian Economy
}

\author{
Esther Ifeanyichukwu Oladejo*, Raphael Oshiobugie Sado ${ }^{* *}$, Judith Chika Uche ${ }^{* *}$ \\ *Lecturer, Department of Estate Management, Nnamdi Azikiwe University, Awka \\ ** Lecturer, Department of Estate Management, Nnamdi Azikiwe University, Awka \\ **:Lecturer, Department of Estate Management, Nnamdi Azikiwe University, Awka
}

DOI: 10.29322/IJSRP.11.09.2021.p11751

http://dx.doi.org/10.29322/IJSRP.11.09.2021.p11751

\begin{abstract}
The Aviation industry is a very critical sector of any developing economy. It's important role in the movement of people, goods and services can never be over-emphasized. It provides a leveling ground for both local and international relationships. Like the health-care sector, it is a sector where sophisticated facilities and equipment are in use. This calls for expertise and professionalism on the part of the facilities manager. It is a sector where mistakes and negligence can never be accepted because lives are involved. The researchers evaluated the inherent challenges of facilities management in the Aviation sector of the Nigerian economy. The study findings include among others, poor safety and security, managerial bureaucratic bottle-necks, poor quality of staff and outdated equipment. The study findings present feasible recommendations based on the study findings. These include bench-marking, continuous professional development/training programmes, accurate inventory keeping and evaluations, provision of adequate incentives and awards, and continuous monitoring and checks and balances.
\end{abstract}

Index Terms- Facilities management, Facilities manager, Aviation, Nigeria.

\section{INTRODUCTION}

$\mathrm{T}$ The history of aviation industry dates back to 1925 , when the first flight into Nigeria landed in Kano. Aviation has become an integral part of the socio-economic life of Nigerians. The development of aviation sector since then has been characterized by many opportunities, some gains and values and some others misfortunes. [1] pointed out that inadequate training in the theories, fundamentals and principles of facilities management has been the bane of the problem of many potential facilities managers. Hence failure in this crucial area becomes colossal.

Transport is a key factor in development and it will continue to play an important role in nation building, since there is always the need to collect, assemble, move or transfer and distribute people and goods. [2] declared "there is no escape from transport". It is an indispensible necessity for every striving economy.

The operation of an airport of a significant size must be able to supply or administer the following facilities; servicing, maintenance and engineering of aircraft, airline operations including aircrew, cabin attendants, ground crew, terminal and office staff, and business necessary for the economic stability of the airport (concessionaires, leasing companies etc), aviation support [2]

Nigeria aviation industry is divided into: Nigerian Airspace Management Agency (NAMA), Nigeria Civil Aviation Authority (NCAA) and Federal Airports Authority of Nigeria (FAAN). The formal development of aviation sector started at the end of the Second World War in 1946 with headquarters in Lagos [3]. Air transport development received federal government special attention in the 1970s, it was more of political and social considerations than economic.

[4] opined that Nigeria's aviation safety record is appalling, as the airspace is regarded as one of the most dangerous, making nonsense of whatever reforms the government had embarked on". According to [5]. Nigerians should stop paying lip service to urgent services like aviation, an industry we cannot afford to operate below standards. The reports of the presidential task force which was set up in 2006 to look into the decay in the aviation sector revealed that all the airports in the country lacked basic operational facilities that could make for smooth operations of modern airports. The decay in the aviation facilities was attributed to long years of neglect and corruption.

\section{OVERVIEW OF THE NIGERIAN CIVIL AVIATION AUTHORITY (NCAA)}

According to [6], the Nigerian Civil Aviation Authority (NCAA) is the statutory regulatory body of the Nigerian Aviation industry. Initially, the Civil Aviation Department (CAD) of the Federal Ministry of Aviation was responsible for the management and maintenance of Nigerian Airports and other navigational facilities. Nevertheless, when the Nigerian Airports Authority (NAA) was created, CAD ceased to exist. The Nigerian Airports Authority commenced operations in 1978.

In line with the recommendations of the National Policy on Civil Aviation in 1989, the Federal Civil Aviation Authority (FCAA) was established by Decree 8 of 1990 to take over all the regulatory functions and provide air traffic and aeronautical telecommunication services. In August 1995, a re-organization of some government establishments within the industry led to the scrapping of the Directorate of Safety Regulation and Monitoring (DSRAM) and the Directorate of Economic Regulation and Monitoring (DERAM) in the Federal Ministry of Aviation, which were respectively charged with the safety and economic regulatory functions of the defunct FCAA [6]. 
[7] posits that the NCAA should ensure stringent air worthiness certification procedures for aircraft, re-orientate air worthiness inspectors on the necessary steps and checks on ageing aircraft, and ensure that the most experienced worker is assigned to inspect ageing aircraft. To proffer solution to the problem of aviation safety and security, [8] maintains that modern security equipment should be procured by the Federal Airports Authority of Nigeria (FAAN), in line with global aviation standard.

[7] also recommends that qualified core professionals with relevant academic qualifications should be injected into the aviation industry. While [8] posits that professionalism of the Ministry of Aviation would put the ministry in good stead, rather than "relying on mediocre for policy formulation and direction".

The Nigerian Civil Aviation Authority was established by Act No. 49 of 26th May, 1999. It effectively commenced operation in January 2000. The mission of the Authority is; to provide aviation safety and economic regulatory services in the most efficient, effective, quality and technology - driven manner, to the satisfaction and benefit of all stakeholders, consistent with the highest international standards and the sustainable development of the industry and national economy. This was predicted earlier, based on the belief that aviation should readily enhance economic and social development.

\section{THE MEANING OF FACILITIES MANAGEMENT}

It is important to note that incessant air mishaps have paved way for concern over air safety in Nigeria. Nevertheless, these mishaps in turn have been aggravated by poor airport safety and security. [9] defined facilities management as a diverse range of vital activities which can simply be summed up as getting the best from buildings for the benefit of the organization and in this view categorized facilities management into a broader dimensions inclusive of support services outside the core business of an organization and having following components: Lease terms and negotiations, rent reviews, Building services, Engineering maintenance etc.

[10] noted that there are certain problems that have been militating against facilities management practice in Nigeria. Some of these problems include; Conception of Idea, Operational Problems, Funding Cost, Assembling the Right Professionals, Inadequate Training of Facilities Manager etc.

The modern form of Real Estate Management can be seen from three different view-points which are called Asset Management (AM), Property Management (PM) and Facilities Management (FM) [2]. In Asset Management the owner and investor concentrate on the profitability of business, in Property Management the technical manager concentrates on the building and its equipment, whilst in Facilities Management practice, the occupant of a workplace is interested in the space and services supporting his/her work or industrial production.

[11] stated that Facilities Management (FM) is applicable to any form of structure or building that affords some space for the housing of certain user activities, equipment and furniture in order to execute jobs with optimum ease and satisfaction while reducing costs. A decade ago, facilities management was seen as the integral planning, realization and management of buildings and accommodation, services and resources which contribute towards the effective, efficient and flexible attainment of organizational goals in a changing environment [12]. The recent trend is to view FM as "the management of non-core company assets to support and increase efficiency of the main business of the organization [13].

[14] defines FM as the practice of coordinating the physical workplace with the people and work of the organization" while the British Institute of Facilities Management [15] defines Facilities Management as the integration of multi-disciplinary activities within the built environment and the management of their impact upon people and the work place. FM uses a multidisciplinary approach to achieve organizational goals using people and the work place. FM is also defined as an integrated approach to maintaining, improving and adapting the buildings of an organization in order to create an environment that strongly supports the primary objectives of that organization [16].

[17] posited that Facilities Management is "the application of the total quality techniques to improve quality, add value and reduce the risks involved in occupying buildings and delivering reliable support services". [17] recognized that the FM role is to meet the business challenges that confront the organization it is supporting, for reaching the optimum balance between people, physical assets and technology. The definition presented by [17] becomes the most appropriate in the context of the area of study under consideration.

The ethical practice in an organization must be refashioned and influenced by the central values of the organization and its internal and external environments. [18] maintains that internal environment of an organization comprises three elements - the set of norms of behavior, defined by the code of ethics; the behavior of top management; and the organizational systems and procedures. All three elements must be rationally managed in order to ensure adequate solution of the problems of bad management. One good method of resolving ethical problem is to have predetermined strict moral principles and adhere to them always; irrespective of the prevailing circumstances.

[14] stated that executives evaluate the facilities management function as follows:

\section{Reduces Costs, Increases Productivity, and Aids Competitiveness:}

Almost all executives report that facilities management makes a positive impact on their organization's productivity and financial bottom - line. However, six in ten think of their facilities as a cost of doing business or a resource that enables the organization to function. It was reported that in their evaluation of facilities management performance, nine in ten executives, on average, said that financial management and project accomplishments skill factors are "very important" considerations. Planning/advisory and communication skills were both very important to about seven in ten, customer service to six in ten, and knowledge to about half. Facilities managers operate as professional role poachers; they try to poach other professional responsibilities which they cannot deliver. It should be noted that these requirements and functions are important but these are not the same thing as saying that FM have the training and expertise to execute them. There are specialists carrying out these roles, and if FM wants to replace them, they should show that their training is superior to those of the existing experts. 
However, all of the skill factors evaluated in the study were rated either very or somewhat important by at least $88 \%$ of the senior managers, indicating that facilities management personnel are expected to offer a wide variety of skills. This is a sweeping conclusion not based on rational and objective evaluation of the training given by existing program to facilities management.

\section{Costs of Desired Facility Management Information:}

Executives are most concerned with receiving accurate and timely information about costs, including budget variations, unexpected repairs, and cost per square foot. Other data commonly considered "essential" are facility status, employee satisfaction with work environment, space utilization, and risk management issues. Executives strongly support providing facility managers and Departments with direct access to senior management, but not in boardroom meetings. All these claims should be x-ray in the context of FM training curricular. Most of the claims are not supported by the range and depth of existing programs

\section{Increasing the Value of Facilities Management:}

Proactive communication, customer service orientation; Executives strongly suggest that facility managers and departments become more proactive in suggesting better equipment and procedures, and improve their ability to make effective needs assessments. Other recommendations for increasing the value of facilities management include:

i. Adopting a customer service orientation

ii. Communicating frequently and pro-actively

iii. Understanding and working toward the organization's goals and mission

iv. Becoming involved in strategic planning

v. Demonstrating added value, by going beyond the traditional view of facility management

vi. Successfully controlling and minimizing costs vii. Keeping up-to-date with technology and ideas

\section{OBSERVED/RECORDED LAPSES IN THE AVIATION SECTOR}

Between what the aviation sector is and what it should be certain factors have been observed to have created the gap. These are:

\section{Safety and Security:}

The maintenance of safety culture in the aviation industry is inevitable. Safety culture, according to [19] refers to a situation in an organization where each individual employee, regardless of position, assumes an active role (supported by the organization) in error prevention. Emphasizing the essence of safety culture, [20] recognizes that operators do not interact with technology in isolation, rather they function "as coordinated teams embedded within a particular organizational culture. [21] argue forcibly that safety initiatives are required to help reduce the frequency of air accidents. They suggest the approach whereby new cockpit technology can be utilized to enable pilots avoid completely adverse weather or recover speedily from hazardous situations. [22] posits that the basic cause of air accidents is the fallible decisions made by designers and high-level managerial decision makers. He identifies two types of errors; active errors (effects of which are felt in no distant time), and latent errors which linger for a long period, and present themselves sequel to the intervention of regulators, internal auditors or accidents, only when they have acted with other factors to collapse a system's defenses. Active errors, according to him, are associated with the actions of air traffic controllers, pilots and control room crews, while latent errors are linked with the actions of maintenance personnel, designers and high-level decision makers. Thus, these errors "pose the greatest threat to safety of a complex system". This is illustrated in the model below.

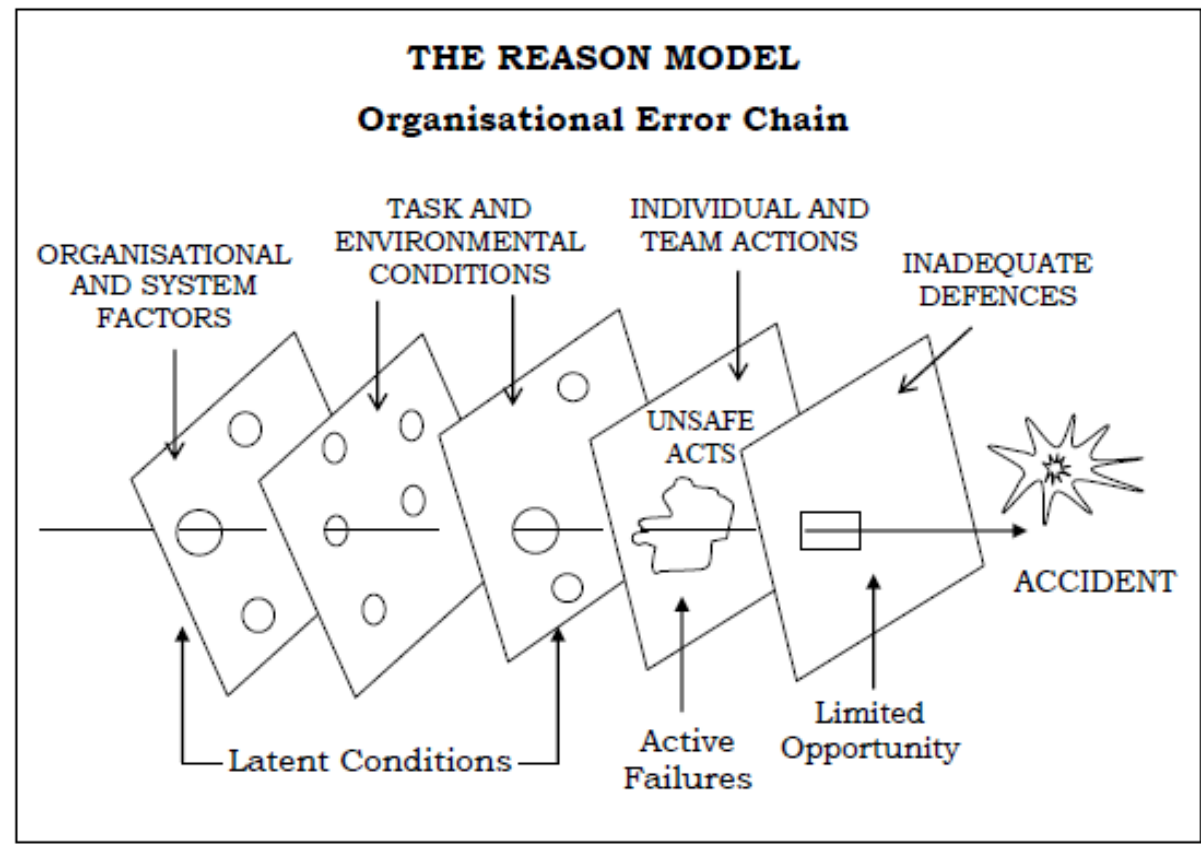

This publication is licensed under Creative Commons Attribution CC BY. 
Figure 1: The Reason Model

Source: [22] Human Error. Cambridge University Press.

\section{Quality of Staff:}

[23] blames air crashes on managerial failure on the part of aviation agencies. [24] maintains that cases of air disasters in Nigeria are not properly investigated, and reports of such investigations are rarely made public, neither are recommendations implemented. Still on the quality of staff employed, [25] has the following to say: "The unprofessionalism displayed by the ground crew of most airlines from check-in counters to the tarmac, often cause passengers to wonder if airline management takes cognizance of the fact that first impressions matter". You cannot really eat your cake and still have it, when an organization decides to use cheap labour to accomplish the tasks distinct specialists, it will be a big joke to expect professionalism. That is the fate of the Nigerian Aviation industry.

[26] maintains that "corruption, short circuiting and corner cutting were the bane of the aviation industry".

In the same vein, [8] laments that the Aviation Ministry is "populated with politicians rather than experts, who know next to nothing". In his work, [27] argues forcibly that corruption and bureaucratic inconsistencies have been observed in the African aviation industry. He maintains that the discrepancy between fees charged by African countries and other countries for the same services is quite significant. [28] emphasizes that Nigeria is notorious for problems with its recording system, as well as billing companies of aircraft that are not even operated by them.

\section{Navigational Facilities:}

With respect to the availability of navigational facilities at the nation's airports, [29] emphasizes that our facilities, quite unlike those of other developed countries, are inadequate and not very functional. There have been complaints about poor radar systems, which are feared to be responsible for the wrong information given from the control towers.

[30] posits that the use of old model radio signal (Beacon 121.5 MegaHertz) by airlines in the country has made search and rescue operations quite cumbersome, even fruitless in some cases. Emphasizing the relevance of information, [31] says: "In Nigeria, there are only two pieces of radar, and these cannot cover the nation's airspace. When it functions, it aids the air traffic controller in doing his job, and where it doesn't, he relies on mental calculation, and you know that there is great danger in speculating in aviation business". Further remarks on navigational facilities, [32] says: "Our airspace was blacklisted by the International Federation of Airline Pilots (IFALPA) as lacking in effective communications, navigation, surveillance and air traffic management facilities, services and procedure.

[33] posits that the aviation industry must make the best advantage of the new technology available - the A380, A340-500 or the new B7E7. These, according to him, will give the airlines new capabilities and change the mode of travel as well as operations. A professional with poor working tools cannot accomplish anything positive. This is a huge challenge faced by professionals in the Nigerian Aviation industry.

\section{THE CONCEPT OF MANAGEMENT}

According to [34] as cited in [35] posited that "management is the utilization of physical and human resources through cooperative efforts, accomplished by performing the functions of planning, organizing, staffing, directing and controlling".

This definition emphasizes the control of resources aimed at achieving the goals of an organization.

[36] defined management as the process of planning, organizing, leading and controlling the work of organization members and of using all available organizational resources to reach stated organizational goals.

Here, management is perceived as a process, based on which four managerial processes have been identified. These include planning, organizing, leading and controlling. 


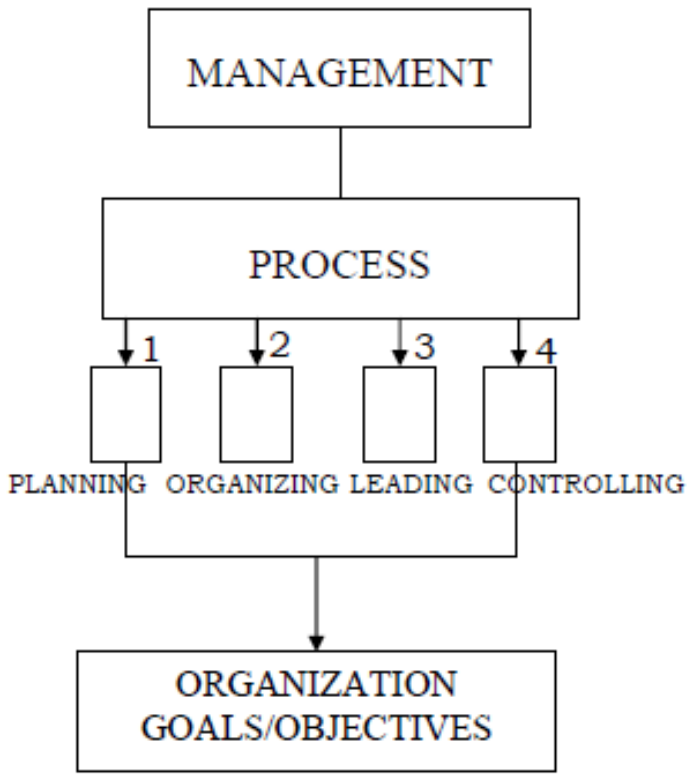

Figure 2: $\quad$ Management as a Process

Source: Oladejo, Sado, Uche (2020);

Evaluation of the Challenges of Facilities Management in the Aviation sector of the Nigerian Economy.

[37] concludes that a process emphasizes that all managers, regardless of their particular aptitudes or skills, engage in certain interrelated activities in order to achieve organizational goals. Management can also be perceived from the perspectives of Organizational Theory, Leadership, Administration, Planning, and Entrepreneurship.

\section{Functions of Management in an Organization}

The four basic functions of management include -

i. Planning

ii. $\quad$ Organizing

iii. Leading

iv. Controlling

\section{Planning:}

Planning entails thinking through organization's goals and actions in advance. It deals with anticipation and forecasting of the future and accomplishment of future objectives.

Planning actually entails the selection of objectives and strategies, policies, programs and procedures for achieving them, either for the entire organization or for any organized part thereof. To a large extent, it involves decision-making, since it involves selecting from among alternatives. Plans are based on the organization's objectives, thus they set up the most appropriate procedures for reaching the stipulated objectives.

They are the guidelines employed by organizations to obtain and commit the resources required to reach set objectives. Through efficient planning, members of the organization carry on activities which are in line with the stipulated objectives and procedures.

Planning also enables management to measure the organization's performance, thus corrective measures can be taken if outcome is not satisfactory. To ensure effective planning, goals are selected for the organization's sub - units, its divisions and departments. Programs are then established for achieving the goals in a systematic manner [38].

\section{The Organizing Process:}

This deals with the allocation of responsibilities and tasks to positions within the organizational structure. It also entails choosing an appropriate organizational structure which will be dictated by the technology and environment of an organization. Since the planning process is implemented through the organizing process, organizing depicts the actual managerial responsibilities in an organization. The organizing function necessitates the design of an appropriate organizational structure which provides for formal relationship as well as the mobilization of human and material resources required for putting the organization's plan into effect.

Effective organization calls for a proper determination of the activities that lead to goal achievement, the grouping of the said activities, a proper assignment of the already grouped activities to a manager, delegation of authority to carry them out, and adequate preparation for the coordination of authority and informational relationship horizontally and vertically in the organization structure.

\section{Leading:}

[36] defines leadership as the process of directing and influencing the task - related activities of group members towards goal - setting and goal attainment.

This function deals with the inter-personal aspect of managing. The most significant problem faced by managers emanate from people's desires and attitudes, their behavior as 
individuals and groups, and the call upon them to also become effective leaders. Leadership implies followership, and people tend to follow those whom they perceive as means of satisfying their own needs, interests and desires. As such a leader uses his intuition and expertise to get his followers to yield to organizational goal accomplishments.

\section{Leadership Functions:}

According to [35], research has shown that groups within an organization need a vibrant employee to perform two major functions as follows-

(i) Task - related or problem - solving functions

(ii) Group - maintenance or social functions.

Social functions entail settling disputes and ensuring that individuals are appreciated by the group. If an individual performs the two roles satisfactorily, he becomes an effective leader.

[35] maintains that, of the three leadership styles identified (Democratic Leadership, Autocratic Leadership and LaizzerFaire Leadership), only the manager who adopts a democratic style of leadership can promote full participation and cooperation in any organization.

\section{Controlling:}

In the real sense, controlling is a component of the planning process. In the course of planning, control measures, which give due information as regards the direction of the implementation process, are designed. Hence, controlling is the process of ensuring that the activities planned are the activities implemented. It entails measuring and correcting the activities of subordinates to ascertain whether events are congruent with plans. It actually matches performance with goals and plans, depicts deviations, and

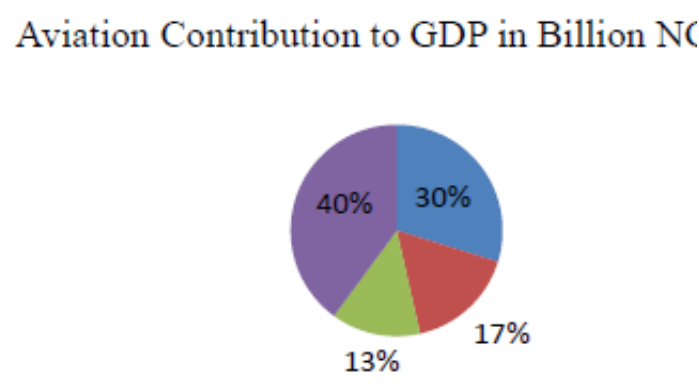

Figure 3: Aviation contribution to GDP of Nigeria

Source: [40] International Air Transport Association (IATA), Airports Council International, Nigeria Bureau of Statistics, Oxford Economics, 2012 puts forward appropriate actions to rectify deviations, thereby assuring the accomplishment of plans.

According to [39], controlling involves four basic elements -

(i) Establishing standards of performance.

(ii) Measuring current performance.

(iii) Comparing this performance with the established standards.

(iv) Taking corrective action if deviations are detected. The control function, if performed satisfactorily, enables the manager to keep the organization on the right track. Organizations are beginning to appreciate and integrate quality into the control function. One popular and effective approach is Total Quality Management (TQM). TQM focuses management on the continuous improvement of all operations, functions, and, above all, processes of work.

\section{BENEFITS AND CONTRIBUTIONS OF AVIATION SECTOR TO ECONOMIC GROWTH OF NIGERIA}

The aviation sector, of recent, contributes NGN 119 billion $(0.4 \%)$ to Nigeria GDP. The total comprises:

A. NGN 59 billion direct contribution through the output of the aviation sector (Airlines, airports and the ground services).

B. NGN 34 billion indirect contribution through the aviation sector supply chain.

C. NGN 27 billion contributed through the spending by the employees of the aviation sector and its supply chain.

D. In addition, there is NGN 78 billion in catalytic benefit through tourism, which raises the overall contribution to NGN 198 billion or $0.6 \%$ GDP.

\section{Employment Ratios}

The aviation sector supports over 159,000 jobs in Nigeria in the same period. The total comprises:

I. Over 44,000 jobs directly supported by the aviation sector.

II. 64,000 jobs indirectly supported by the aviation sector.

III. Over 51,000 jobs supported through the spending by the employees of the aviation sector and its supply chain.

IV. In addition there are further 130,000 people employed through the catalytic (tourism) effect of aviation. 
ISSN 2250-3153

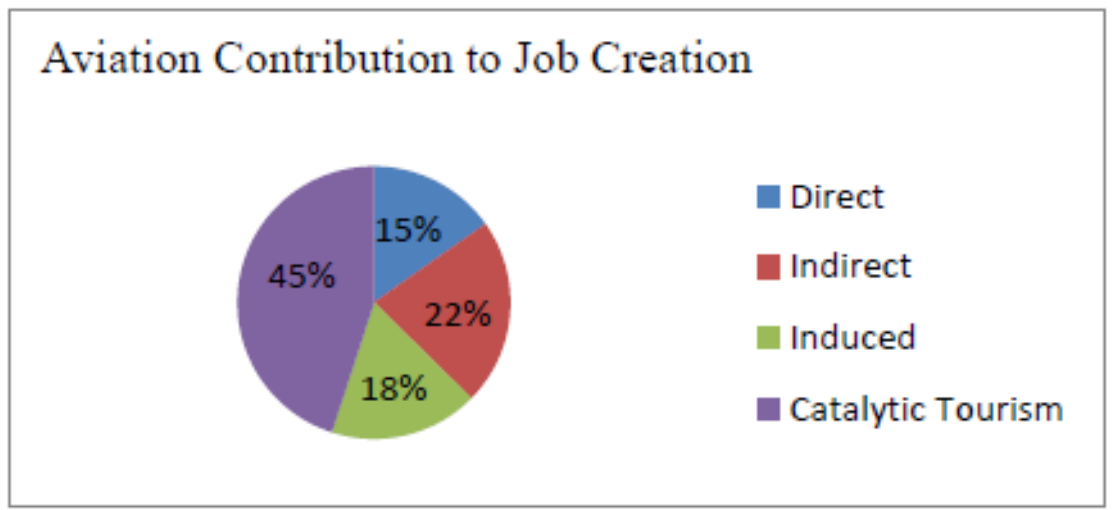

Figure 4: $\quad$ Aviation contribution to job creation in Nigeria

Source: [40] IATA, ACI, Nigeria Bureau of Statistics, Oxford Economics, 2012

The average air transport services employee generates NGN 3.5 million in Gross Value Added (GVA) annually, which is nearly 7 times more productive than the average in Nigeria. Aviation sector pays over NGN 8.5 billion in tax including income tax receipts from employees, social security contributions and corporation tax levied on profits, with further NGN17.0 billion of revenue coming from Value
Added Tax (VAT) on domestic and international flights originating in Nigeria. It is also estimated that an additional NGN 8.9 billion of government revenue is raised via the aviation sector's supply chain and another NGN7.1 billion through taxation of the supported activities by the spending of employees of both the aviation sector and its supply chain.

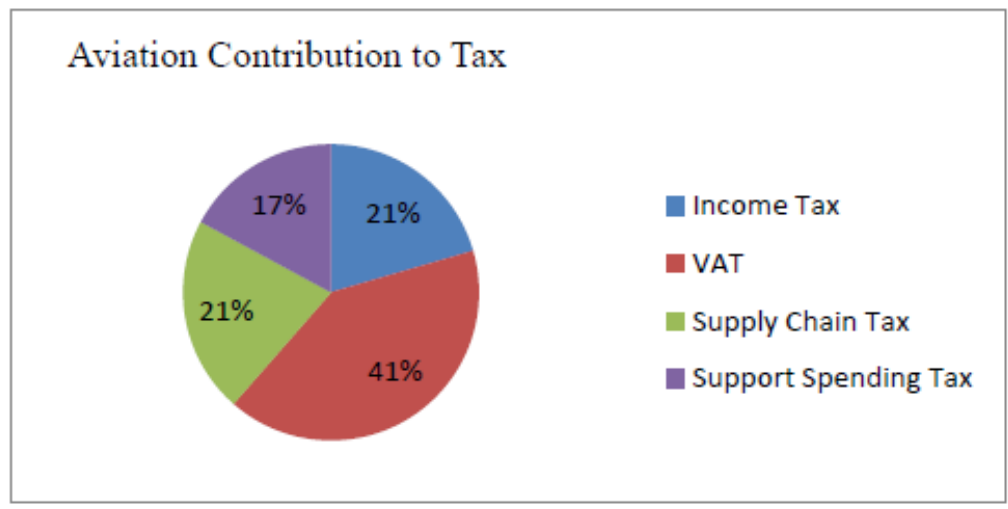

Figure 5: Aviation contribution to tax revenue of Nigeria

Source: [40] IATA, ACI, Nigeria Bureau of Statistics, Oxford Economics, 2012

Air transport infrastructure comprises the airports, air navigation, airlines and other essential ground services. This carries over 8.3 million passengers and 1.5 million tonnes of air freight to, from and within Nigeria. With this, we calculate that air passengers and shippers valued the air transport services they used at over NGN1, 651 billion and NGN 127 billion respectively. With the above amounts, the consumer benefits derived on travel expenditure was NGN 785 billion for passengers and shipper benefits NGN 37 billion on freight.

Table 1: Aviation's contribution of output and jobs to Nigeria

\begin{tabular}{|c|c|c|c|c|c|}
\hline Aviation contribution & Direct & Indirect & Induced & Total & \% of whole Economy \\
\hline \multicolumn{7}{c|}{ Contribution to GDP (NGN Billions) } \\
\hline Airlines & 29 & 17 & 11 & 58 & $0.2 \%$ \\
\hline Airports and Ground Service & 29 & 16 & 16 & 61 & $0.2 \%$ \\
\hline Total & 58 & 33 & 27 & 119 & $0.4 \%$ \\
\hline Catalytic (Tourism) & 40 & 24 & 15 & 78 & $0.3 \%$ \\
\hline Total including Catalytic & 98 & 57 & 42 & 197 & $0.6 \%$ \\
\hline
\end{tabular}




\begin{tabular}{|c|c|c|c|c|c|}
\hline \multicolumn{7}{|c|}{ Contribution to Employment (000) } \\
\hline Airlines & 7 & 33 & 21 & 61 & $0.1 \%$ \\
\hline Airports and Ground Service & 37 & 31 & 30 & 97 & $0.2 \%$ \\
\hline Total & 44 & 64 & 51 & 159 & $0.3 \%$ \\
\hline Catalytic (Tourism) & 64 & 37 & 29 & 130 & $0.2 \%$ \\
\hline Total including Catalytic & 107 & 101 & 80 & 289 & $0.5 \%$ \\
\hline
\end{tabular}

Source: [40] IATA, ACI, Nigeria Bureau of Statistics, Oxford Economics, 2012

The total annual passengers were domestic (To and from within Nigeria) $=4.2$ million and International Passenger was 4.1 million Passengers respectively. More than 15,200 scheduled international flights depart Nigeria annually for 32 airports in 30 countries while over 66,800 flights provide over 7.5 million seats to passengers for 18 airports within Nigeria.

The total payment of the above passenger was NGN 866 billion (inclusive of tax) and those within Nigeria residents paying around NGN434 billion while international payment was NGN 432 billion, the benefit to traveler is worth NGN 785 billion a year and NGN 397 billion for Nigerian residents.

Air transport is crucial for the distribution of value weight product. Nigeria account for only $0.5 \%$ of the total tonnage of global trade with the rest of the world and in value terms it makes up to $34.6 \%$. Freight forwarders pay airlines NGN 89 billion annually to carry 181000 Tons of freight to, from and within Nigeria. The shipper benefit in excess of this expenditure is estimated as NGN 37 billion and based on the share of exports trade. The shippers receive nearly $60 \%$ of the benefit NGN 22 billion.

In 2010 Air transport route, Nigeria was connected to 48 routes to urban agglomerations around the world. A total of 11 of these routes were connecting Nigeria to international cities of more than 10 million inhabitants with 4.8outbound flights per day. Passengers benefitted from 30 outbound flights per day from Abuja to Lagos Airport and from 13 flights per day from PortHarcourt to Lagos Airport for business and leisure purpose, visiting family and friends.

Nigeria's integration into the global air transport network transforms the possibilities for the Nigerian economy by:

i. Raising productivity and hence the economic longrun supply capacity.

ii. About $10 \%$ improvement in connectivity relative to GDP would see a NGN 20 billion per annum increase in long-run GDP for the Nigeria economy.

iii. Opening up foreign investment and markets to Nigerian economy.

iv. Enlarge and increase export activities of Nigerian business activities.

v. Create employment and job opportunities for Nigeria.

vi. Encourage and aid speedy delivery of cargoes and goods just-in-time inventory management that quicken reliably transportation of essential supplies.

vii. Generate revenue to both the government and airlines operators.

viii. Flexibility of skilled labor supply which enhance all locative efficiency and reduce the rate of unemployment. ix. Increase easy access to exchange of goods, services and information internationally.

As at 2017 air transport in Nigeria supports more than 650,800 jobs including tourism related while contributing $\$ 8.2$ billion to the Country's GDP [41]. However the aviation industry has not fully reached its potential in contributions to economic growth. A look into the Nigerian's Aviation Sector reveals that the sector currently contributes \#149.4 billion, an estimation of $0.12 \%$ as at 2018 to the economy [42]. This is very inadequate considering the great potentials of the Nigerian Aviation industry.

\section{CHALLENGES OF FACILITIES MANAGEMENT IN NIGERIAN AVIATION SECTOR}

There are a lot of challenges in the aviation sector and most of these challenges are facilities management issues even though finance and lack of adequate and functional facilities can be a cause but the bottom line is that these issues borders around the roles facility management plays in such large organizations where utmost safety, security and comfort are of immense importance. The following are some of the facility management problems in the aviation industry:

(1) Lack of appropriate Professionals: There is no better professional in managing the aviation industry than the facilities manager because he is an all rounder but unfortunately the aviation industry has little of these professionals. [8] laments that the Aviation Ministry is "populated with politicians rather than the experts, who know next to nothing", he then posits that professionalism of the Ministry of Aviation would put the ministry in good stead, rather than "relying on mediocre for policy formulation and direction" This lack of right professionals coupled with the quality of the staff explains some of the reasons for managerial failure including air crashes that has been recorded over time in Nigeria.

(2) Bad Management: To effectively perform the functions of management (planning, organizing, directing, controlling), managers must be equipped with adequate professional skills. Where such skills are inadequate or absent, bad management is imminent, which ends up reducing the smooth flow of activities and in turn loss of revenue because when customers are not satisfied with the management style, patronage is lost to other serious private Airports.

(3) Absence of coherent air transport policy: There is no coherent policy that will ensure balance between the needs of the society and the economy for adequate transport facilities and the ability of the transport sector to meet such demands. A facilities manager ought be close to the decision makers to ensure such a policy is formulated because this is geared towards customer 
satisfaction and future continuity plans and continuous realization of the organization goals, this is lacking in the aviation sector in Nigeria and even when some policy is formulated, management and employees still indulge in doing the wrong thing. Indeed, the facilities manager should be part and parcel of the Aviation policy management committee for effective implementation of policies.

(4) Overstretched Facilities: Facilities have started decaying, this is because they have been used beyond the capacity required. The practice of good facilities management ensures their repairs, maintenance, capacity and replacement subsequently. Life cycle estimate of facilities and crucial equipment are not adhered to. Recall the case of the Boeing airplane that was already abolished in other countries but Nigeria was still flying them. When facilities management is lacking in the aviation industry, a lot is overlooked. Increase in human traffic should call for an upgrade in these facilities. When facilities are decaying, it presents a bad name or image of the country to outsiders/Investors. It is needless reiterating that airports are very vital to the socioeconomic development of the country.

(5) Lack of Vision for the Organization: [43] defines vision as the description of something (as organization, a business, an activity) in the future. It is the mental perception of the kind of environment an individual, or an organization, aspires to create within a broad time horizon and the underlying condition for the actualization of this perception. Lack of vision therefore, implies disability to discover new alternatives that will guarantee future survival and prosperity for the organizations. Every organization strives for continuous improvement in their modus operandi in order to be at par with acceptable standards.

(6) Loose security: The roads leading to airports in Nigeria are not so secured and can be invaded by armed robbers or militants who attack travellers, there is no solid perimeter fencing most of the airports, this is another aspect of the facility management, the right professionals being employed together with the collaborative efforts of the organization can provide the needed finance that will ensure the needed security. The facilities manager should do well to advice the organization that security and safety should not be jeopardized for any reason.

(7) Ineffective Communication: Communication is the process by which management informs subordinates of the tasks and resources required to fulfill certain organizational obligations. The relevance of effective communication therefore, cannot be overemphasized. Poor communication in organizations occurs as a result of bad organizational climate, conflict, poor working conditions, and poor attitude of managers (some managers take hasty decisions). The Facility Manager most times lacks the leadership quality and the team spirit to proactively carry his subordinates along in their daily task and worse still during emergency situations. Personal disputes should be put aside in working environments but unfortunately most facility mangers in this part of the world carry their personal grievances concerning a subordinate even right into emergency situations. Failure to communicate effectively can lead to huge crisis in the work environment and can even threaten the safety and security of the customers. No relationship strives without good communication. The ability to communicate effectively is an essential quality of a facilities manager, if he must succeed.

(8) Lack of incentives: Facility managers work so hard in most airports in Nigeria to ensure safety of humans, avoid air crashes, increase patronage, carry out repairs and maintenance, negotiate with vendors and suppliers, carries his team along, make the environment comfortable for both his subordinates and customers, develops himself professionally to meet up with technology for the handling of the airport facilities and compete in the global market, maintain effective communication to ensure smooth flow of activities etc yet he is not paid well for a whole lot of duties and more, this can result to lack of focus and vision for the organization, he may carry out his task carelessly because at the end of the day, he is not even paid well. The aftermath effect of low wage/salary and lack of bonuses is low passion and desire to carry out his duties effectively and this could result to serious loss in management task and profit realization directly and indirectly. Incentives and adequate remuneration have over decades proved to be a motivating factor for employees. Even a child that is regularly commended always works harder for more commendation, how much more adult workers.

(9) Nepotism/Ethnic Favouritism: According to [44], this is termed implicit favourite model. Managers have their choice of candidates that they wish to favour, and they do everything within their powers in a bid to have their way, even to the detriment of the organization.

(10) Unpatriotic Attitude to Work: At all levels of hierarchy in an organization, employees are obliged to portray total loyalty to the organization. However, if organization members in both private and public enterprises, compromise the organization's interests vis-à-vis external bodies, this depicts lack of patriotism to the organization.

(11) Unethical Conducts/Behaviours: As ethics deals with what is right as distinct from what is wrong; what is good, as distinct from what is bad, unethical conducts implies that management and employees indulge in activities that violate the ethics of their positions. This is obvious in the way and manner aviation staff treat their passengers/customers. Sometimes, they are very rude in dealing with passengers over minor issues or misunderstandings that can be professionally handles.

\section{CONCLUSION}

Facilities management is very important in the aviation sector because it holds the key to the growth and infrastructural development of the nation. Apart from the lack of funding and bureaucracies that have hindered the Aviation industry from reaching its full potentials, the introduction of the Facilities Management practice would help in realizing the positive prospects of the industry. This would not only boost the revenue generated but place them as one of the top industries in the competitive market. The activities of national airlines are measured with the development supported with the Nigeria-based airlines that were responsible for carrying $66 \%$ of passengers and freight. Gross profits, tax and wages, revenues created by these airlines aid the Nigerian economy in generating a multiplier effects on Nigerian national income or GDP. The major benefits to customers and their welfare can be found in the part these airlines play in providing the connectivity infrastructure between Nigeria and overseas cities and markets.

Aviation sector has a significant benefit in the Nigerian economy through adequate facilities management, supporting Nigeria with GDP of about $4 \%$ and job creation of about 159,000 
of Nigerian working force, contribution to tourism industry and foreign investment in Nigeria economy. An annual tax paid NGN 8.5 billion. Passenger VAT of NGN 17 billion with NGN 8.9 billion government revenue and another supply chain of NGN 7.1 billion through taxation.

With all the above contribution to the Nigerian economy by aviation sector, and its operational ability to connect the Nation to the outside world is of great impact which needs to be sustained and improved upon to increase its economic value and operation, improve aviation infrastructure and expand its operation to more international markets for wider operations.

There are more to be considered for efficient operation, if the government policies are designed to meet critical infrastructure for the country's long term success in global aviation market and avoid future safety risk. The Nigerian government should improve the connectivity index which is a measure of the quality of a country's air transport network that reflects both the volume of passengers' traffic and the importance of the destinations served.

\section{THE WAY FORWARD IN THE AVIATION INDUSTRY}

Having evaluated the challenges faced by the Nigerian Aviation industry, the study recommends the following as effective measures for improved aviation services:

(1) Involvement of facilities management professionals: For the umpteenth time, facilities managers are the right experts for management of facilities in the aviation industry, their training to ensure safety, security, and comfort in the work environment while reducing costs and maximizing profits gives them advantage over other professionals.

(2) Benchmarking: It takes humility to learn from a successful business counterpart. The Nigerian Aviation Industry can be upgraded in standards and modes of operation if it benchmarks her foreign counterparts in developing countries. Their method of operation can be emulated to improve the standard in Nigeria.

(3)Continuous Training Programmes/Professional development: In the face of continuous evolving technology, aviation personnel should undergo continuous development/training programmes to be abreast of continuous standard practices and innovations.

(4) Accurate Inventory Keeping and Evaluations: The facilities manager should have an accurate record of the organizations inventories. This includes a list of crucial facilities and equipment in constant daily use. These should be evaluated periodically putting into consideration their maintenance requirements and life estimates. This will ensure that they do not break down at crucial hours they are needed. Also it will remove the risk of using facilities or equipment that has outlived their life cycle estimates.

(5) Recruitment of Professionals with Proven Track Records: The aviation industry is a sector where safety is very critical. Standards should not be lowered in recruiting qualified professionals with proven good track records. This guarantees expertise and excellent performance on the job.

(6) Scheduled Periodic Maintenance: The facilities manager ought to ensure that scheduled periodic maintenance of the facilities and crucial equipment are not compromised or neglected. This can be ensured by sending reminders to the management at a reasonable time before the scheduled maintenance period.

(7) Continuous Monitoring and Checks and Balances: There should be close knit monitoring and checks and balances to curtail corrupt practices. Monitoring teams should be created to ensure that funds set aside for maintenance services are not diverted or embezzled.

(8) Provision of Adequate Incentives and Awards: Mouth watering incentives and awards of excellence should be provided by the aviation management for outstanding staff. This will encourage dedication to duty and also rekindle the interest of poorly performing staff.

(9) Striving to be Exceptional: To embrace and consolidate ideal management, bad management must be discarded, and a culture of excellence built. Consequently, the competitive stress of globalization can be faced. The business environment is highly dynamic and competitive. Managers operating within the environment must search for ways of unleashing the creative potentials of employees. One way to do it is the creation of corporate culture that is excellence supportive. This will involve systematic and articulated human resources management, creation of fit between strategy and culture, establishment of ethical standards, building spirit of performance into the culture and bonding the fits through shared values. In the local and global market, the facility manager together with his management team should map out strategy that should go beyond putting them in the market but at the forefront. New innovations together with doing things efficiently, excellently and exceptionally would put the Nigeria Aviation industry at the top above their competitors.

(10) Effective communication: Facility manager should ensure effective communication at all levels for hitch-free operations. The organizations communication gadgets should be the state of the art, reliable and functional at each point in time.

\section{REFERENCES}

[1] 1 Oladejo, E. I. Problems of Facilities Management in Corporate Organizations in Lagos State. A Study of Some Selected Manufacturing Industries, (Published M.Sc. Thesis University of Nigeria), (2009).

[2] 2 Gleave, S. D. Study on Employment and Working conditions in Air Transport and Airports. DG MOVE, European Commission. [2015].

[3] 3 Filanim M. O. The role of National Tourist Associations in in the preserving of the Environment in Africa. Journal of Travel Research, (1975)

[4] 4 Shadare, W. "Aviation: The Rot Has Gone Really Deep", The Guardian, Nov. 5. (2006)

[5] 5 Okon, O. "From further Losses to Air Caskets", The Guardian, Dec. 16 (2005).

[6] 6 Nigerian Civil Aviation Authority (NCAA), History of NCAA Retrieved 7th January, 2020 from https://ncaa.gov.ng/about/history-of-ncaa. (2020)

[7] 7 Dike, P. "The Rot in Aviation”, The Guardian, Nov 1. (2006).

[8] 8 Ore, D. "Aviation and Challenges of 2007", The Guardian, Jan. 5 (2007).

[9] 9 Jordan A. CIOB Handbook of Facilities Management. Longman Group Limited. (2000)

[10] 10 Osagie, J. U. Problems of Management of Facilities in Public Enterprises. A Study of Federal Secretariat Complex, Ikoyi, Lagos: (Unpublished M.Sc. thesis), University of Lagos. (2004).

[11] 11 Oladejo, E. I. Evaluation of Challenges of Facilities Management in Tertiary Healthcare Institutions in South East Nigeria. (Published Ph.D 
Dissertation), NnamdiAzikwe University Awka, Anambra state, Nigeria. (2014).

[12] 12 Regterschot, J. Facility Management in Changing Organizations. Proceedings of the International Symposium on PropertyMaintenance Management and Modernization 1. CIB InternationalCouncil for Building Research Studies and Documentation WorkingCommission 70, Singapore. (1990).

[13] 13 Nelson, M. L. and Alexander, K. The Emergence of Supply Chain Management as a Strategic Facilities Management Tool, in: Alexander, K. (Ed) Proceedings of the Euro FM Research Symposium in Facilities Management, Salford, UK: University of Salford. (2002).

[14] 14 IFMA. International Facility Management Association. Retrieved September 04th, 2017 from http://www.ifma.com. (2010).

[15] 15 BIFM. British Institute of Facilities Management. Retrieved November 25th, 2017 from http://www.bifm.org.uk/bifm/ home. (2010).

[16] 16 Barrett, P. S. Facilities Management. Towards Best Practice. Blackwell Science, London: Oxford Press. (1995).

[17] 17 Alexander, K. Facilities Management: Theory and Practice Management. 2 (1). The Emergence of Facilities Management in the U.K. New York: Spoon Press. (1996).

[18] 18 Ike, O. Managing your Organization's Ethical Climate, LSB Management Review Vol. 7 No. 1. (2002).

[19] 19 Eliff, G. Organizational Safety Culture, Proceedings of the Tenth International Symposium on Aviation Psychology, Columbus, $\mathrm{OH}$ : Department of Aviation. (1999).

[20] 20 Wiegmann, D. A; Zhang, H; Thaden, T. L; Sharma, G. and Mitchell, A. A. A Synthesis of Safety Culture and Safety Climate Research, University of Illinois: Aviation Research Lab, Technical Report ARL-02-03/FAA-02-2. (2002).

[21] 21 Johnson, N; Wiegmann, D and Wickens, C. Effects of Advanced Cockpit Displays on General Aviation Pilots' Decisions to Continue Visual Flight Rules Flight into Instrument Meteorological Conditions, Proceedings of the Human Factor and Ergonomics Society 50th Annual General Meeting, April 5. (2006).

[22] 22 Reason, J. T. Human Error, Cambridge: Cambridge University Press. (1990).

[23] 23 Onyeka, B. V. "A Nation's Year of Pain and Anguish in Aviation", The Guardian, Dec. 28. (2005).

[24] 24 Ningi, M. A., "Frequent Air Disasters: Time for Sanity", The Guardian, Dec. 13. (2005)

[25] 25 Amogu, N. "How Safe are Nigerian Airlines?" Business Times, Jan. 69. (2005).

[26] 26 Obasanjo, O. "Avoiding disasters in the nation's aviation sector", The Guardian, Nov. 1. (2006).

[27] 27 Conlyn, G. African Aviation Needs Consistency, Transport World Africa, Vol. 1 No. 8 37-39. (2003).

[28] 28 Beer, J. Developing an Aviation Safety Strategy within Southern African Context: A Stakeholder Perspective Unpublished Thesis. (2005).

[29] 29 Tukur, M. "Safety at the Airports", The Guardian, June 24. (2005).

[30] 30 Anuforo, E. "A Disaster and the Nation in Disarray", The Guardian, Oct. 30. (2005).
[31] 31 Orebiyi, K. "We have to take Information Serious", The Guardian, Oct 30. (2005).

[32] 32 Onasanya, O. "Reaching for Safer Skies with Certification", The Guardian, March 7. (2005).

[33] 33 Tong, Y. C. "Why Singapore is a World Leading Aviation Hub", The Guardian, June 25. (2004).

[34] 34 Resser and Dyikuk, J. G Promoting the Concept of Participatory, Cooperative and Collaborative Management", Interworld Journal of Management and Development Studies, Vol. 1 No. 1. . (2002).

[35] 35 Dyikuk, J. G. Promoting the Concepts of Participatory, Co-operative and Collaborative Management, Inter-world Journal of Management and Development Studies, Vol. 1 No. 1. (2002).

[36] 36 Stoner, J. ET. AL Management, New Delhi: Prentice Hall. (2000).

[37] 37 Mintzberg, H. The Nature of Management: New Jersey: Prentice Hall. (1973).

[38] 38 Guardian of 24th January, (2003).

[39] 39 Onyemelukwe, C. C. Men and Management in Contemporary Africa. London: Longman Groups Limited. (1973).

[40] 40 Oxford Economics Brochure. Economic Benefits from Air Transport in Nigeria. (2012).

[41] 41 Adekola, S 'Air Tranport Contributes $\$ 8.2$ bn to Nigeria's GDP-IATA'. Nigerian Tribune, 17th August. Available at www.tribuneonlineng.com. Accessed 17th March 2020. (2017).

[42] 42 Olaoluwa, J. 'Aviation Sector to Contribute over \#1.2 Trillion to Nigeria's GDP by 2020' Nairametrics, 28th August. Available at http://nairametrics.com>2019/08/28. Accessed 17th March, 2020. (2019).

[43] 43 Kazmi, A. Business Policy and Strategic Management: New Delhi: Tata Mc. Graw Hill. (2003)

[44] 44 Ekpo - Ufot, A. A Technique in Organization Design and Decision Making: A Derivation from Organization Theory, An Outline Model Paper for Business, Department of Business Administration, University of Lagos. (1987).

\section{AUTHORS}

First Author - Esther Ifeanyichukwu Oladejo, Department of Estate Management, Nnamdi Azikiwe University, Awka. estheroladejo2@yahoo.com

Second Author - Raphael Oshiobugie Sado, Department of Estate Management, Nnamdi Azikiwe University, Awka. valuersado@gmail.com

Third Author - Judith Chika Uche, Department of Estate Management, Nnamdi Azikiwe University, Awka. judithchika503@gmail.com

Correspondence Author - Raphael Oshiobugie Sado, valuersado@gmail.com, +2348039501432 